\title{
浮力秤量法によるWOエマルションの液滴径分布測 定
}

\begin{tabular}{|l|l|}
\hline 著者 & 澤田 紋佳, 島津 昌光, 大平 勇一, 平野 博人 \\
\hline 杂誰志名 & 化学工学論文集 \\
\hline 巻 & 45 \\
\hline 号 & 5 \\
\hline ページ & 184 187 \\
\hline 発行年 & 2019-09-20 \\
\hline URL & ht t p: //hdl . handl e. net /10258/00010050 \\
\hline
\end{tabular}




\title{
浮力秤量法による $\mathrm{W} / \mathrm{O}$ エマルションの液滴径分布測定
}

\author{
澤田 紋佳 ${ }^{1 \dagger \dagger} \cdot$ 島津 昌光 ${ }^{1} \cdot$ 大平 勇一 ${ }^{1}$. 平野 博人 ${ }^{2}$
}

1 室蘭工業大学大学院工学研究科 環境創生工学系専攻, 050-8585 北海道室蘭市水元町 27-1 2 苫小牧工業高等専門学校 創造工学科, 059-1275 北海道苫小牧市錦岡 443

キーワード： エマルション，液滴径，沈降速度，浮力, Stokes 式

\begin{abstract}
浮力秤量法によるエマルション中の液滴径分布の測定可能性について検討した. 連続相には 油相としてn-ドデカン, 分散相には水相としてイオン交換水を使用し， W/O エマルションを 調製した. 浮力秤量法により得られた水滴径分布は, 顕微鏡法により得られた分布と一致した. W/O エマルション中の液滴径分布は，浮力秤量法により測定することができる.
\end{abstract}

\begin{abstract}
緒言
エマルションは化学工業のみならず，新エネルギー分野や食品 分野などでも使用されている. エマルション中に分散している液 滴のサイズは反応や抽出の効率, 流動性などに影響をおよぼす. そのため, 各種操作を行う上で, 液滴径分布は必須の情報である. 液滴径の測定には顕微鏡法（例えば, Takahashi et al., 1986), 遠心 式粒度測定装置（例えば，Kitamura et al., 1994），などが主に用い られている. しかし，顕微鏡法は多数の液滴径を測定する必要が あるため時間がかかる. 一方, 遠心式粒度測定装置は高価であり， 中小企業等では使用頻度を勘案すると導入に二の足を踏む場合が ある。

我々は，安価で簡便に使用できる固体粒子の粒径分布測定法と して浮力科量法の開発を行ってきた（Obata et al., 2009; Ohira et al., 2010; Furukawa et al., 2010; Tambun et al., 2016). 浮力科量法はアル キメデスの原理を利用する方法である．懸濁液中の粒子移動に伴 って生じる眯濁液の密度変化を眯濁液中に吊るした科量棒に作用 する浮力として検知し, 秤量棒長さ, 秤量棒のみかけ質量の経時 変化から粒径分布を求める. 粒径分布測定装置は床下积量フック 付の精密電子天秝, 懸濁液の密度変化を感知寸るために䀣濁液中 に吊される秤量棒, データロガー兼解析装置として使用するパソ コンで構成される。科量棒のみかけ質量から粒径分布を計算する 方法は沈降天秤法（Odén, 1925） と同様，積算型となる.

固体粒子の場合, JIS 試験用粉体など規格化された試験用試料を 用いた検定が可能である. 前報（例えば，Obata et al., 2009）で示 したように, 浮力科量法の理論で用いる式は秤量棒に作用する力 の収支式および Stokes 式により構成される. 固体粒子が液滴にか わった場合，理論で用いる Stokes 式に液滴の内部循環を補正寸れ ば適用可能である.
\end{abstract}

そこで本研究では, 擋拌槽を用いて W/O エマルションを調製し 浮力称量法および顕微鏡法による液滴径分布と比較することで, 浮力科量法による液滴径測定可能性について検討した.

\section{1. 理論}

$\mathrm{W} / \mathrm{O}$ エマルションを構成する分散相の密度を $\rho_{\mathrm{d}}$, 連続相密度を $\rho_{\mathrm{c}}$, 液滴の初発濃度を $C_{0}$ とすると, $\mathrm{W} / \mathrm{O}$ エマルションの初発密度 $\rho_{\mathrm{e} 0}$ は次式で求められる.

$$
\rho_{\mathrm{e} 0}=\rho_{c}+\frac{c_{0}}{\rho_{\mathrm{d}}}\left(\rho_{\mathrm{d}}-\rho_{\mathrm{c}}\right)
$$

密度 $\rho_{\mathrm{B}}$ の积量棒の体積を $V_{\mathrm{B}}$ とすると, エマルション中の科量棒 に作用寸る浮力 $W_{0}$ および秎量棒に作用するみかけの力 $G_{0}$ は次式 で表される.

$$
W_{0}=V_{\mathrm{B}} \rho_{\mathrm{e} 0} g
$$

$G_{0}=V_{\mathrm{B}} \rho_{\mathrm{B}} g-W_{0}=V_{\mathrm{B}}\left(\rho_{\mathrm{B}}-\rho_{\mathrm{e} 0}\right) g$

時間の経過とともに液滴は連続相中を沈降し，分散相の粘性抵 抗のため大きな液滴ほど沈降速度は大きくなる．秤量棒下端より も下まで沈降した液滴は秤量棒に感知されないことから，この状 態の W/O エマルション密度 $\rho_{\mathrm{e}}$, 称量棒に作用する浮力 $W$ および みかけの力 $G$ は，次式で表すことができる.

$$
\begin{aligned}
& \rho_{\mathrm{e}}=\rho_{c}+\frac{c}{\rho_{\mathrm{d}}}\left(\rho_{\mathrm{d}}-\rho_{\mathrm{e}}\right) \\
& W=V_{\mathrm{B}} \rho_{\mathrm{e}} g \\
& G=V_{\mathrm{B}} \rho_{\mathrm{B}} g-W=V_{\mathrm{B}}\left(\rho_{\mathrm{B}}-\rho_{\mathrm{e}}\right) g
\end{aligned}
$$

全液滴が科量棒下端よりも下まで沈降すると, 科量棒は液滴濃度 を感知しない，この状態での W/O エマルション密度 $\rho_{\mathrm{e} \infty}$, 科量棒 に作用寸る浮力 $W_{\infty}$ およびみかけの力 $G_{\infty}$ は次式から求められる.

$$
\begin{aligned}
& \rho_{\mathrm{e} \infty}=\rho_{\mathrm{c}} \\
& W_{\infty}=V_{\mathrm{B}} \rho_{\mathrm{c}} g \\
& G_{\infty}=V_{\mathrm{B}} \rho_{\mathrm{B}} g-W_{\infty}=V_{\mathrm{B}}\left(\rho_{\mathrm{B}}-\rho_{\mathrm{c}}\right) g
\end{aligned}
$$

液滴径を $x$, 液滴径分布関数を $f(x)$. 液滴の沈降速度を $v(x)$, 秤量 棒の長さを $h$ とする. 時刻 $t_{\mathrm{i}}$ で秤量棒下端よりも上に存在する液 滴濃度を $C$ とすると, 秝量棒下端よりも下に存在する液滴濃度 $C_{0}$ $-C$ は次の物質収支式で表される。 


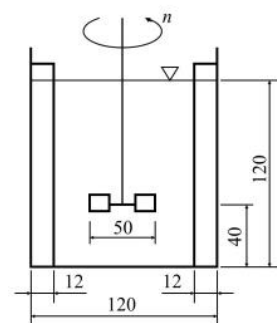

(a)

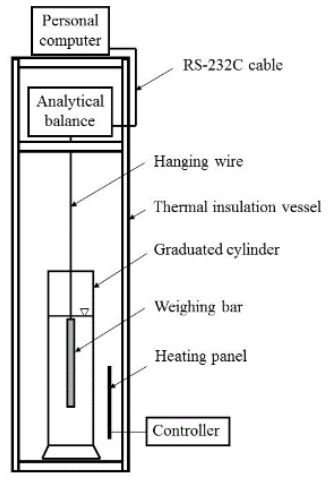

(b)
Fig.1 Schematic diagrams of experimental setup

$$
C_{0}-C=C_{0} \int_{x_{i}}^{x_{\max }} f(x) d x+C_{0} \int_{x_{\min }}^{x_{i}} \frac{v(x) t}{h} f(x) d x
$$

Equation (10)の右辺第 1 項は, 沈降速度 $h / t_{\mathrm{i}}$ に相当する液滴径 $x_{\mathrm{i}}$ よ り大きな液滴の濃度を示し, 右辺第 2 項は液滴径 $x_{\mathrm{i}}$ より小さい液 滴のうち, 科量棒下端よりも下に存在する液滴の濃度を示す。こ れを称量棒に作用するみかけの力 $G$ の収支式で表すと, 次式のよ うになる.

$$
\begin{aligned}
G-G_{0}=\left(G_{\infty}-G_{0}\right) & \int_{x_{i}}^{x_{\max }} f(x) d x \\
& +\left(G_{\infty}-G_{0}\right) \int_{x_{\min }}^{x_{i}} \frac{v(x) t}{h} f(x) d x
\end{aligned}
$$

これを時間 $t$ で微分し, Eq. (11)に入れて整理すると, 次式が得ら れる.

$$
G=G_{R}+\left(\frac{d G}{d t}\right) t
$$

ここで,

$$
G_{R}=V_{B} \rho_{B} g-W_{0}+\left(W_{0}-W_{\infty}\right) \int_{x_{i}}^{x_{\max }} f(x) d x
$$

である. 積算百分率 $D$ は Eq.(12)の切片 $G_{\mathrm{R}}$ を用いて, 次式より求 めることができる.

$$
D=100-R=100-\left(\frac{G_{R}-G_{0}}{G_{\infty}-G_{0}}\right) \times 100
$$

なお, 重力加速度 $g$ は定数とみなせるため, 積算百分率 $D$ は科量 棒のみかけ質量 $M(=G / g)$ を測定することで求めることができる.

また，時刻 $t$ までに秤量棒上端から下端までの距離 $h$ を沈降す る液滴の沈降速度 $v(x)$ は次式で表される.

$$
v(x)=\frac{h}{t}
$$

よって, 沈降速度 $v(x)$ を持つ液滴の直径 $x$ は, 分散媒粘度を $\mu_{\mathrm{c}}$ と すると, Stokes 式に液滴の内部循環を補正する Hadamard の補正項 （例えば, Ervik et al., 2017）を組みこんだ Eq. (16)により求めるこ とができる.

$$
x=\sqrt{\frac{18 \mu_{c} h}{g\left(\rho_{d}-\rho_{c}\right) t} \times\left(\frac{3 \mu_{d}+2 \mu_{c}}{3 \mu_{d}+3 \mu_{c}}\right)}
$$

\section{2. 実験装置および方法}

\subsection{W/O エマルションの調製と顕微鏡によるる水滴径分布測定}

$\mathrm{W} / \mathrm{O}$ エマルションは, 連続相となる油相として $n$-ドデカン (関 東化学製, 密度 $\rho_{\mathrm{c}}=750 \mathrm{~kg} \cdot \mathrm{m}^{-3}$, 粘度 $\left.\mu_{\mathrm{c}}=1.38 \times 10^{-3} \mathrm{~Pa} \cdot \mathrm{s}, 298 \mathrm{~K}\right)$, 分散相となる水相としてイオン交換水（密度 $\rho_{\mathrm{d}}=997 \mathrm{~kg} \cdot \mathrm{m}^{-3}$, 粘 度 $\mu_{\mathrm{d}}=0.890 \times 10^{-3} \mathrm{~Pa} \cdot \mathrm{s} ， 298 \mathrm{~K}$ ）で調製した。乳化剂には Span80 (モノオレイン酸ソルビダン, 関東化学製) を用いた. Figure 1 (a) に W/O エマルション調製用擋拌槽の概略図を示す. 水一 $n$-ドデ カン系 W/O エマルションの調製には邪魔板付ステンレス鋼製擋

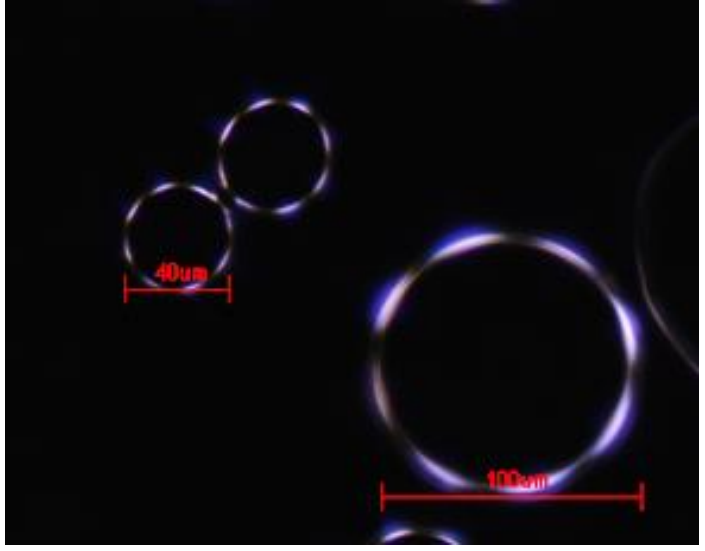

Fig.2 Photograph of W/O emulsion

拌槽（内径 $120 \mathrm{~mm}$ ，高さ $150 \mathrm{~mm}$ ）を使用し，6枚平羽根ディス クタービン翼(直径 $50 \mathrm{~mm}$ ) を槽底から $40 \mathrm{~mm}$ の位置に設置した。 撹汼槽に Span80を $0.04 \mathrm{~mL}$ 加えた $n$ ードデカンを $1300 \mathrm{~mL}$ を入 れ，撹挥速度 $600 \mathrm{rpm}$ で擋拌した. 約 $5 \mathrm{~min}$ 擋拌したところで定常 に達したとみなし, 回転軸に沿ってイオン交換水 $13 \mathrm{~mL}$ を入れた. その後, $30 \mathrm{~min}$ 擋挥し, 水滴濃度 $1 \mathrm{vol} \%$ となる水一 $n$-ドデカン系 $\mathrm{W} / \mathrm{O}$ エマルションを調製した。 なお，固体の浮上性粒子を用いて 固体濃度 $0.1-3 \mathrm{vol} \%$ で粒径分布測定を行い，0.1-1 vol\%では同じ 結果が得られることを確認している(Motoi et al., 2010). そこで, 水滴濃度を $1 \mathrm{vol} \%$ に設定した。

撹拌後, 調製した水一 $n$ ードデカン系 W/O エマルションはガラ ス製メスシリンダーに $1000 \mathrm{~mL}$ 移し, 後述する浮力科量法による 水滴径分布の測定に用いた. 残りの $300 \mathrm{~mL}$ から約 $10 \mathrm{~mL}$ の水 $-n$ 一ドデカン系 W/O エマルションを採取し，USB デジタル顕微鏡 (YDU-2N, 600× 八州光学工業製) により水滴を観察・撮影し, 100 個以上の水滴について横方向 Feret 径を測定した. そのデータ を基に，体積基準の水滴径分布を作成した.

\section{2 浮力秤量法による水滴径分布の測定}

水滴径分布の測定に用いた浮力科量装置を Figure 1 (b) に示寸. 測定装置は前報（Obata et al., 2009; Ohira et al., 2010; Furukawa et al., 2010）と同様に，精密電子天科（GR-300，最小読取質量 $0.1 \mathrm{mg}$, エー・アンド・ディ製), データロガーであるノート型パソコン, $1000 \mathrm{~mL}$ ガラス製メスシリンダー（直径 $65 \mathrm{~mm}$, SIBATA 製)，縦 $500 \mathrm{~mm}$, 横 $500 \mathrm{~mm}$, 高さ $1200 \mathrm{~mm}$ のアルミニウムアングル製の フレーム，気流や温度変化等の外乱を防止するためのアクリル樹 脂製の風除板および実験温度を $298 \mathrm{~K}$ で一定に維持するためのヒ 一ターからなる. 連続相が $n$ ードデカンであるため, 分散相が付着 しづらいポリテトラフルオロエチレン樹脂製秤量棒（ $\phi 10 \times 200$ $\mathrm{mm}$, 密度 $\left.2.20 \times 10^{3} \mathrm{~kg} \cdot \mathrm{m}^{-3}\right)$ を用いた，精密電子天科は RS-232C を介してノート型パソコンに接続し, 精密電子天科付属のソフト ウェアを用いて科量棒の見かけ質量を自動計測できるようにした 揫量棒は上端が W/O エマルション液面から $5 \mathrm{~mm}$ 下の位置になる ように設置した。

前述の方法で調製した水一 $n$-ドデカン系 W/O エマルション $1000 \mathrm{~mL}$ をメスシリンダーに移し，精密電子天科より吊るされた 秤量棒を水一 $n$-ドデカン系 $\mathrm{W} / \mathrm{O}$ エマルション中に入れた. この 時点を時刻 $0 \mathrm{~s}$ として科量棒のみかけ質量を $3 \mathrm{~s}$ 間隔で計測した. 測定を開始し，秤量值が一定となった時点で測定を終了した．得 られたデータに対して理論に基づく計算処理を施し，水滴径分布 


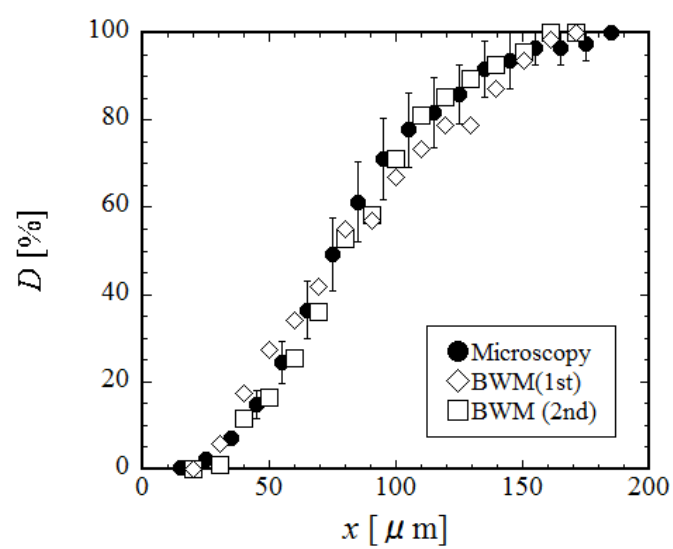

Fig.3 Droplet size distributions of W/O emulsion

を求めた。

\section{3. 実験結果および考察}

\section{1 顕微鏡法による水滴径分布の測定}

Figure 2 に水 $-n$-ドデカン系 W/O エマルション中の水滴サイ ズの計測に用いた顕微鏡写真の一例を示す. 水滴形状を観察した 結果，ほぼ球形であった。 そこで, 横方向 Feret 径を測定し, 水滴 径分布を作成した．顕微鏡法による水滴径分布の測定は別試料を 調製することで 3 回行った. 多少の違いは見られたものの, ほぼ 同じ分布が得られた. 3 回の測定で得られたデータを体積基準の 水滴径分布に換算してから平均值および標準偏差を求めた。 その 結果を Figure 3 に示す. Fig.3 中に平均值を○でプロットし, 標準 偏差をエラーバーで示した. 今回の調製条件で得られた水一 $n$-ド デカン系 W/O エマルション中の水滴径は前述したように多少の バラツキがあるものの, ほぼ対数正規分布に従い, 水滴径範囲は 10-190 $\mu \mathrm{m}, 50 \%$ 径は $75 \mu \mathrm{m}$ ，分布の分散は $1.5 \mu \mathrm{m}$ であった.

\section{2 浮力秤量法による水滴径分布の測定}

Figure 4 に擋汼槽で調製した水一 $n$-ドデカン系 W/O エマルシ ヨン中に眯垂した秤量棒のみかけ質量の経時変化を示す. 同図で は, 科量棒のみかけ質量の初発值 $M_{0}$ を引いた $M-M_{0}$ で経時変化 を示した，再現性確認のため，同条件で 2 回の測定を行った. 時 間の経過とともに $n$-ドデカン中の水滴は沈降し, 秤量棒のみか け質量 $M-M_{0}$ は増加した. $n$-ドデカン中に分散している水滴が 沈降することで, 秤量棒周辺の水滴の濃度が低下する. 科量棒周 辺の W/O エマルションのみかけ密度が小さくなり, 秤量棒に作用 する浮力が小さくなることで科量棒のみかけ質量が増加したため である. その後, ほぼ一定の值となった.これは, 全ての水滴が科 量棒より下に沈降したことで, 秤量棒周辺が連続相の $n$-ドデカ ンのみとなり, 科量棒のみかけ質量 $M-M_{0}$ がこれ以上変化しなく なったためである。この挙動は, 沈降性固体粒子の場合と同様で ある（例えば, Obata et al., 2009). 再現性を確認するため, 別途, 同条件で調製した水ー $n$-ドデカン系 $\mathrm{W} / \mathrm{O}$ エマルションを用いて 科量棒のみかけ質量の経時変化を確認した. その結果, ほぼ同じ 結果が得られた。 以上のことから, 浮力秤量法による液滴径分布 の測定可能性が示された.

続いて, Figure 4 の秤量棒のみかけ質量の経時変化から理論に 基づいて水滴径分布を求めた．その分布を Figure 3 に示す．実験

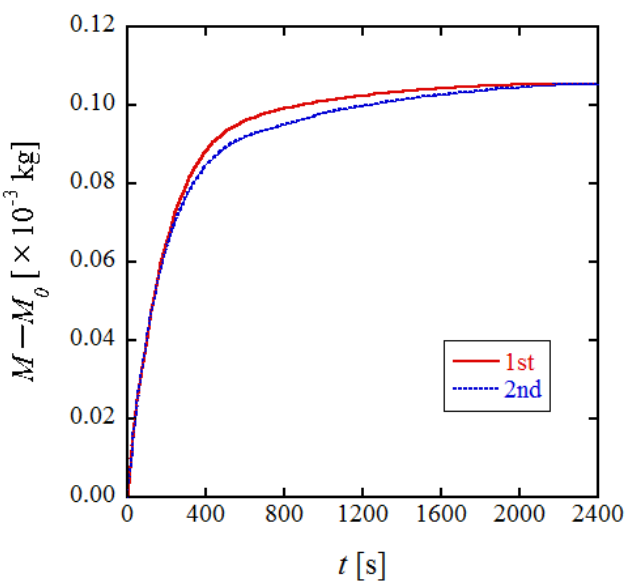

Fig.4 Apparent mass of the weighing-bar as a function of time

は再現性確認のため 2 回行った. 浮力科量法により得られた水滴 径分布は, 2 回とも $20-170 \mu \mathrm{m}$ の範囲であり，ほぼ対数正規分布 に従った. 測定 1 回目の $50 \%$ 径は $74 \mu \mathrm{m}$, 分布の分散は $1.3 \mu \mathrm{m}$, 測定 2 回目の $50 \%$ 径は $77 \mu \mathrm{m}$ ，分布の分散は $2.3 \mu \mathrm{m}$ であった．同 図中に示されている顕微鏡法のデータと比較するとほぼ一致して いる.この結果から, 浮力科量法を用いて W/O エマルション中の 液滴径分布を測定できることがわかった.

\section{結}

浮力科量法による液滴径測定可能性について検討することを目 的として, 撹挥槽で水一 $n$-ドデカン系 W/O エマルションを調製 し, 浮力科量法および顕微鏡法によって測定した水滴径分布を比 較した。その結果，原理の異なる 2 つの方法で測定した水滴径分 布はほぼ一致した．浮力科量法で液滴径分布を測定できることが わかった。

[謝 辞］ 本研究を行うにあたり八田祐紀君に協力いただきました． ここに記して謝意を示します.

\section{Nomenclature}

$=$ concentration of emulsion

$D \quad=$ mass percentage undersize

$f(x) \quad=$ droplet size distribution function

$\left.\mathrm{kg} \cdot \mathrm{m}^{-3}\right]$

$=$ gravitational acceleration

$[-]$

$=$ apparent force of weighting-bar

$\left[\mathrm{m} \cdot \mathrm{s}^{-2}\right]$

= submerged length of the weighing-bar

$[\mathrm{N}]$

[ $\mathrm{m}$ ]

$=$ apparent mass of weighing-bar

[kg]

$=$ time

[s ]

$=$ settling velocity

$\left[\mathrm{m} \cdot \mathrm{s}^{-1}\right]$

$=$ submerged volume

$\left[\mathrm{m}^{3}\right]$

= buoyancy of the weighting-bar

[kg]

$=$ droplet size

$[\mathrm{m}$ ]

$=$ density

$=$ viscosity

$\left[\mathrm{kg} \cdot \mathrm{m}^{-3}\right]$

$[\mathrm{Pa} \cdot \mathrm{s}]$

<Subscripts>

$\begin{array}{ll}\mathrm{B} & =\text { weighing-bar } \\ \mathrm{c} & =\text { continuous phase } \\ \mathrm{d} & =\text { dispersed phase } \\ \mathrm{e} & =\text { emulsion } \\ \max & =\text { maximum }\end{array}$




\begin{tabular}{|c|c|}
\hline $\mathrm{m}$ & $=$ measured \\
\hline $\min$ & $=$ minimum \\
\hline 0 & $=$ initial \\
\hline 50 & $=50 \%$ \\
\hline$\infty$ & $=$ infinity \\
\hline
\end{tabular}

\section{Literature cited}

Ervik, А̊., and E. Bjørklund; "The transition in settling velocity of surfactant-covered droplets from the Stokes to the Hadamard-Rybczynski solution," EJM/B Fluids, 66, 10-19 (2017)

Furukawa, K., Y. Ohira, E. Obata and Y. Yoshida; "Measurements of Mineral Particle Size Distributions by a Buoyancy Weighing Method," Journal of MMIJ, 126, 577-582 (2010)

Kitamura Y., Q. Huang and T. Takahashi; "Superheating and Flashing of Water-inOil Emulsions," Kagaku Kogaku Ronbunshu, 20, 405-410 (1994)

Motoi, T., Y. Ohira and E. Obata, Measurement of floating particle size distributions by a buoyancy weighing-bar method, Powder Technology, 201, 283-288
(2010)

Obata, E., Y. Ohira and M. Ohta; "New Measurement of a Particle Size Distribution by a Buoyancy Weighing-Bar Method," Powder Technol., 196, 163-168 (2009)

Odén, S.; "The Size Distribution of Particles in Soils and the Experimental Methods of Obtaining Them," Soil Science, 19, 1-35 (1925)

Ohira, Y., K. Furukawa, R. Tambum, M. Shimadzu and E. Obata; "Buoyancy Weighing-Bar Method: - A Particle Size Distribution Measurement using New Settling Method -," Jour. Sed. Soc. Japan, 69, 17-26 (2010)

Takahashi T., Y. Kitamura, S. Okazaki and T. Korenaga; "Effect of Water-Soluble Organic Substance on Coalescence Rate of Water-in-Kerosene Emulsion," Kagaku Kogaku Ronbunshu, 12, 327-333 (1986)

Tambun, R., K. Furukawa, M. Hirayama, M. Shimadzu, S. Yamanaka and and Y. Ohira; Measurement and Estimation of Particle Size Distributions by the Buoyancy Weighing-Bar Method and the Rosin-Rammler Distribution at Construction Sites, J. Chem. Eng. Japan, 48, 229-233 (2016)

\title{
Measurement of Droplet Size Distribution in W/O Emulsion by the Buoyancy Weighing-bar Method
}

\author{
Ayaka SAWADA ${ }^{1}$, Masamitsu SHIMADZU ${ }^{1}$, Yuichi OHIRA ${ }^{1}$ and Hiroto HIRANO ${ }^{2}$ \\ 1 Division of Sustainable and Environmental Engineering, Graduate School of Engineering, Muroran \\ Institute of Technology, 27-1 Mizumoto-cho, Muroran-shi, Hokkaido 050-8585, Japan \\ 2 Department of Engineering for Innovation, National Institute of Technology, Tomakomai College, 443 \\ Nishikioka, Tomakomai-shi, Hokkaido 059-1275, Japan
}

Keywords: Emulsion, Droplet size, Settling, Buoyancy, Stokes equation

The possibility of measuring the droplet size distribution in the emulsion by the buoyancy weighing-bar method was investigated. The $\mathrm{W} / \mathrm{O}$ emulsion was prepared using $n$-dodecane as the oil phase for the continuous phase and ion-exchanged water as the aqueous phase for the dispersed phase. The water droplet size distribution measured by the buoyancy weighing-bar method agreed with that measured by the microscopy method. The droplet size distribution in the W/O emulsion could measure by the buoyancy weighing-bar method. 